\title{
Knowledge, self-efficacy and attitudes of Greek primary schoolchildren towards Cardiopulmonary Resuscitation
}

\author{
Polyzou E. ${ }^{1,2}$, Karatzaferi C. ${ }^{1}$, Efthymiou G. ${ }^{3}$, Digelidis N. ${ }^{1}$ \\ ${ }^{1}$ Department of Physical Education and Sport Science, University of Thessaly, Trikala, Greece \\ 2Department of Anaesthesiology, General Hospital of Trikala, Trikala, Greece \\ ${ }^{3}$ Department of Rheumatology and Clinical Immunology, University General Hospital of Larissa, Larissa, Greece
}

Purpose: The benefits of teaching CPR in schools are now well documented, both for increasing the number of bystanders available to assist in emergency situations and also for the personal and social skills the training provides for schoolchildren. ${ }^{1}$ Many countries have already successfully implemented CPR training into school education with impressive results. ${ }^{2}$ In Greece CPR training has not yet been legislated as mandatory part of the course curriculum and the response of schoolchildren to the CPR training is unknown. In our efforts to provide evidence in support of the integration of CPR in primary education in Greece, we assessed how a 3-hour CPR training lesson, conducted by teachers, affected knowledge, selfefficacy and attitudes towards CPR in Greek schoolchildren, 11 to 12 year-old.

Materials and Methods: The project was approved by the local University Ethics Committee, the Ministry of Education and local educational authorities. Schoolchildren (aged 11-12 years, $6^{\text {th }}$ grade) in Trikala and Kalabaka, Greece, received a 3-hour CPR lesson, based on the ERC Guidelines for Resuscitation 2015. Nine teachers, recently trained in CPR for the purposes of this study, delivered the lessons. The schoolchildren's levels of knowledge about CPR, their self-efficacy in performing CPR and attitudes towards learning CPR were measured using a specifically designed questionnaire, ${ }^{3}$ both pre- and post-training.

Results: A total of 106 schoolchildren (65 females) across five primary schools completed this study. Training improved their scores significantly in all three questionnaire's sections: knowledge scores improved from $66 \% \pm 0.09 \%$ to $84 \% \pm 0.09 \%$ (Figure $1, p<0.01$ ), selfefficacy from $3.21 \pm 0.83$ to $3.74 \pm 0.69$ (Figure 2, $p<0.01$ ) and attitudes from $4.51 \pm 0.54$ to $4.77 \pm 0.36$ (Figure $3, p<0.01$ ).

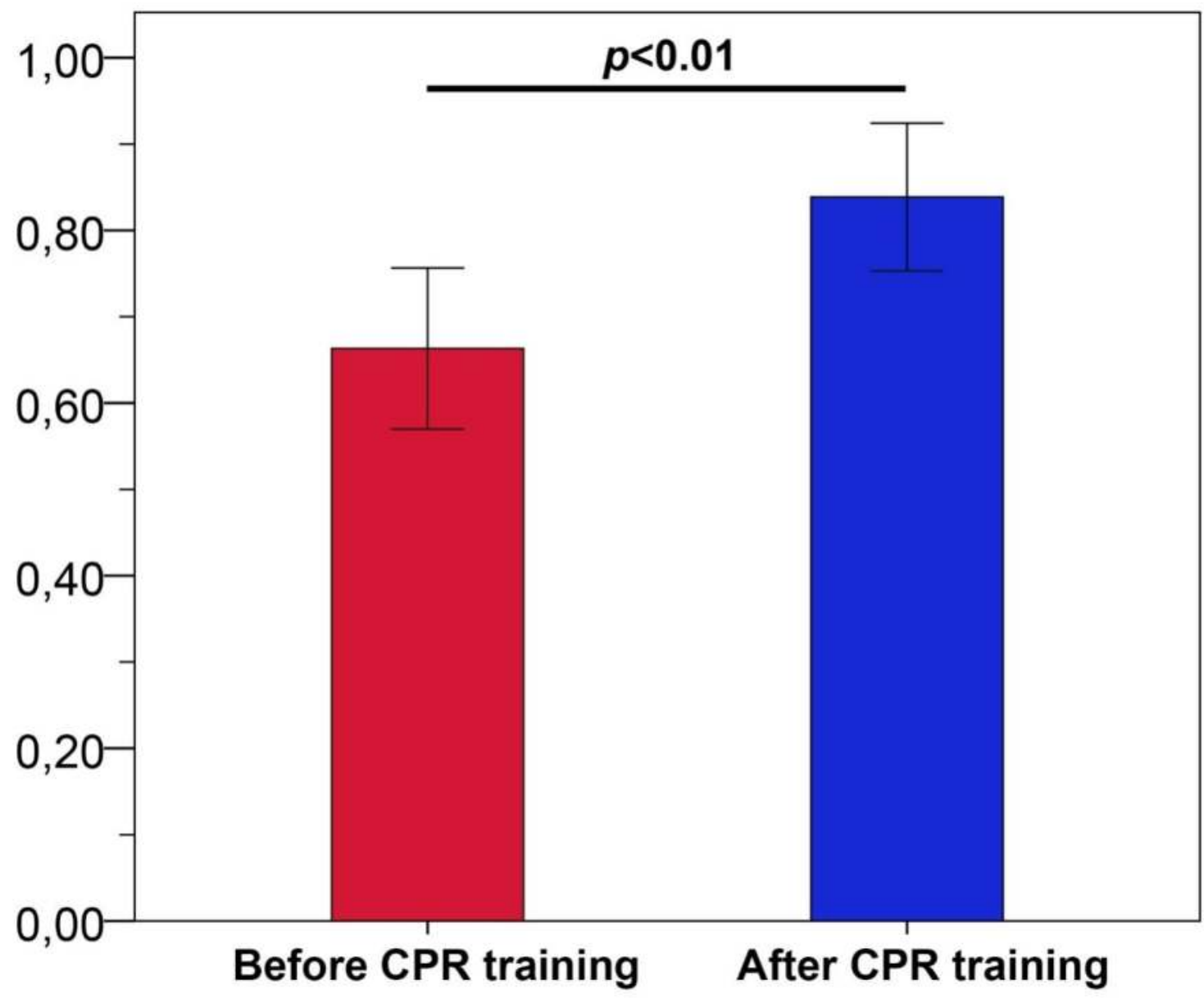

Figure 1: Student's knowledge about CPR scores improved after CPR training. Data represent mean \pm standard deviation. Abbreviation: CPR, Cardiopulmonary Resuscitation.

\section{References}

1. Wilks \& Pendergast Health Education Journal 2017;1-15

2. Bohn et al. Curr Opin Crit Care 2015; 21: 220-225

3. Engeland et al. Inj Control Saf Promot. 2002; 9(2):99-106

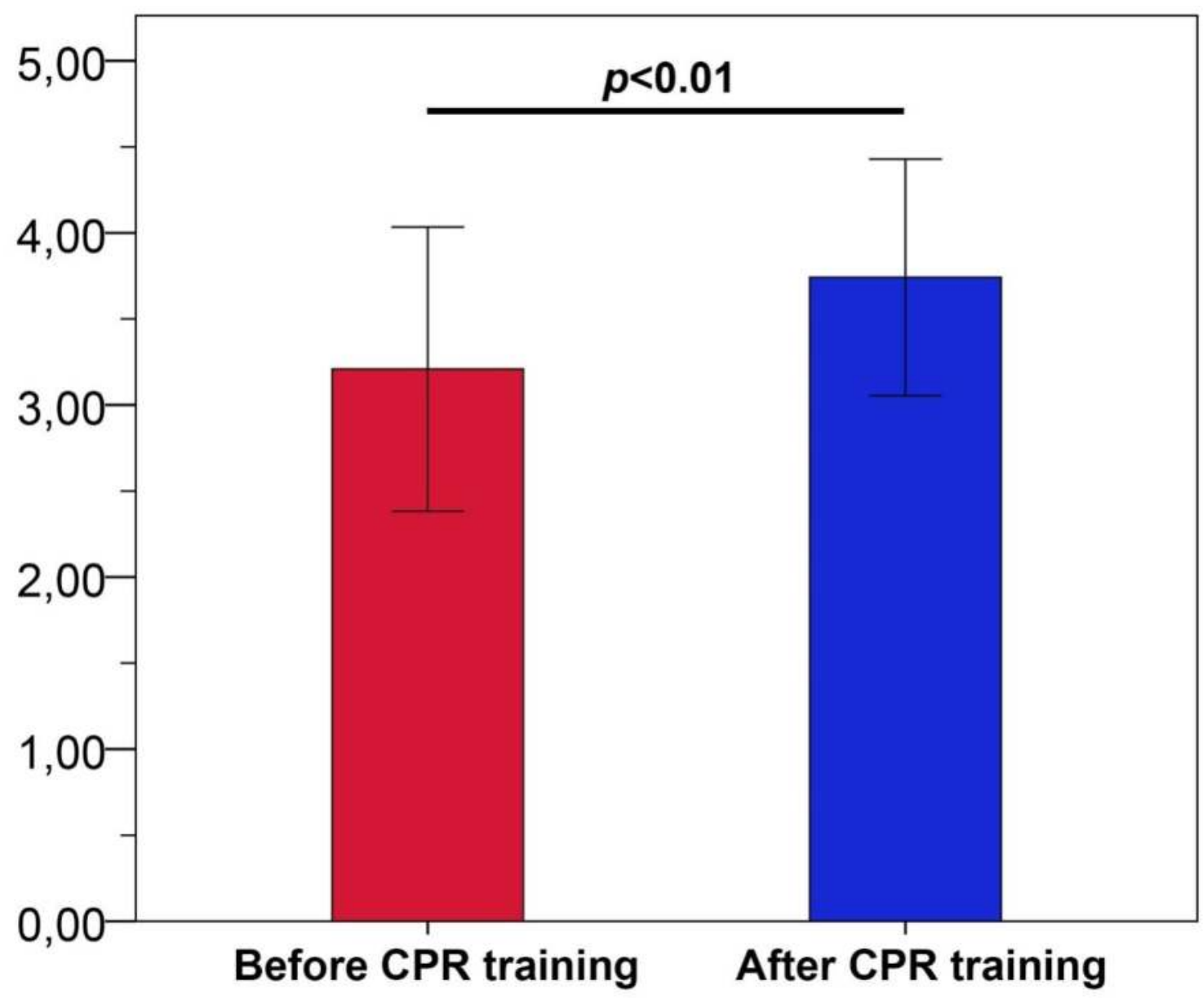

Figure 2: Student's self-efficacy in performing CPR scores improved after CPR training. Data represent mean \pm standard deviation. Abbreviation: CPR, Cardiopulmonary Resuscitation.

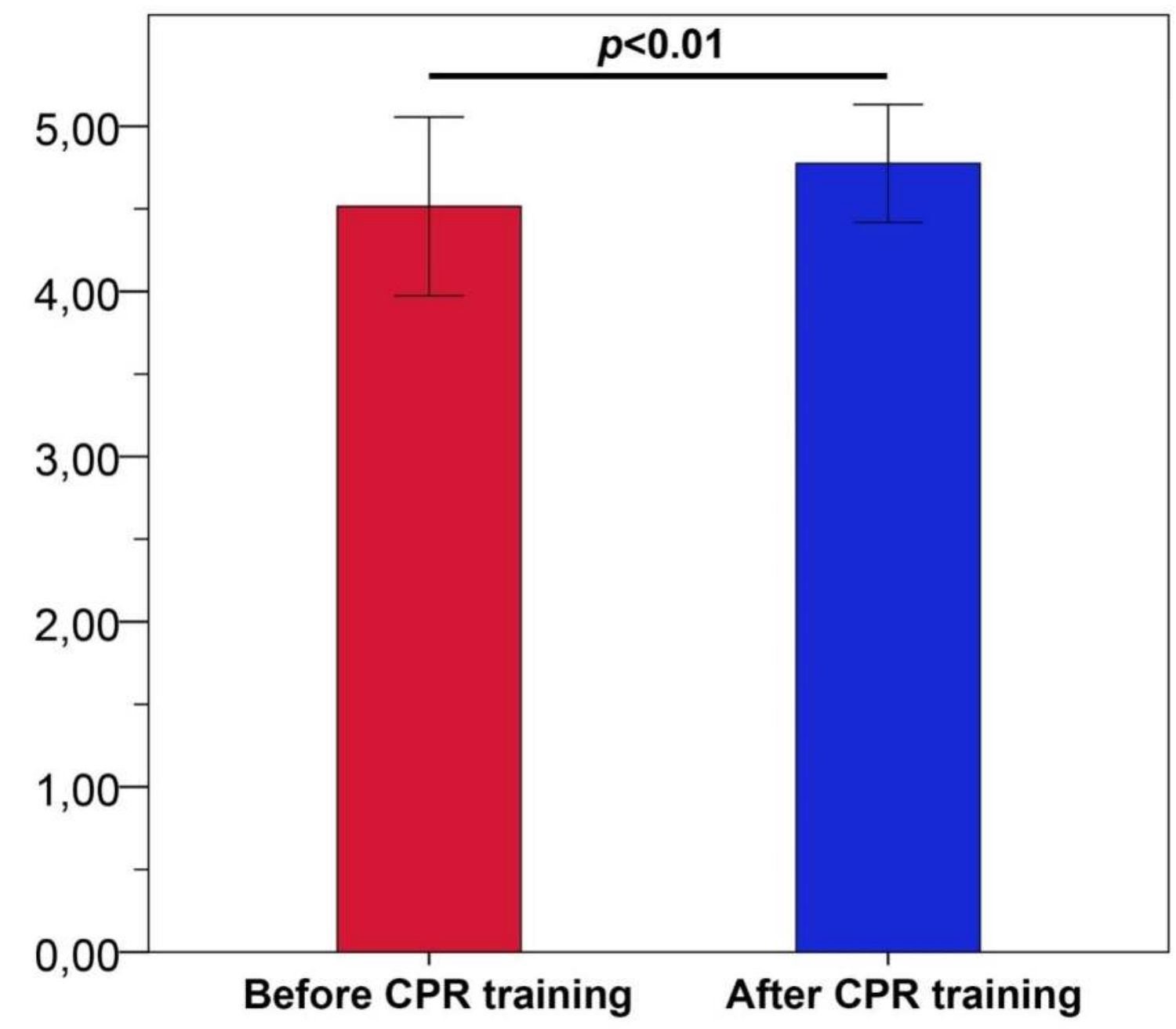

Figure 3: Student's attitude towards learning CPR scores improved after CPR training. Data represent mean \pm standard deviation. Abbreviation: CPR, Cardiopulmonary Resuscitation.

Conclusions: This study clearly demonstrates that a 3-hour ERC guideline-compliant CPR training lesson, conducted by teachers, to 11-12 years old children, imparted new knowledge, enhanced the children's belief in their own ability to perform CPR and improved their attitudes towards learning CPR. In addition, this study, a first for the Greek educational system, proves that the education of schoolchildren in CPR can be implemented within the school setting by the existing teaching staff. We propose that these results further support our call for the provision of CPR training as a mandatory part of the curriculum in the Greek school, as well as for measures to allow the relevant training of teaching staff.

Acknowledgments: 'Information Campaign and CPR Education - Kids save lives' Karatzaferi et al Ministry of Education, Research and Religious Affairs, October 2015 renewed by Diggelidis et al up to 2016. $\Phi 14 / 2139 / 164466 / \Delta 1, \Phi 15 / 2309 / 191230 / \Delta 1$. 